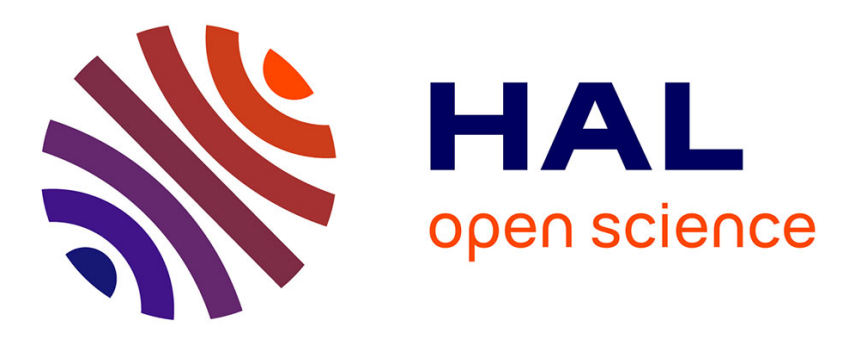

\title{
What do children understand? Communicating health behavior in a European multicenter study
}

Antje Hebestreit, Katharina Maria Keimer, Holger Hassel, Annunziata

Nappo, Gabriele Eiben, Juan Miguel Fernández, Eva Kovacs, Helen Lasn, Monica Shiakou, Wolfgang Ahrens

\section{To cite this version:}

Antje Hebestreit, Katharina Maria Keimer, Holger Hassel, Annunziata Nappo, Gabriele Eiben, et al. What do children understand? Communicating health behavior in a European multicenter study. Journal of Public Health, 2010, 18 (4), pp.391-401. 10.1007/s10389-010-0316-z • hal-00535306

\section{HAL Id: hal-00535306 https://hal.science/hal-00535306}

Submitted on 11 Nov 2010

HAL is a multi-disciplinary open access archive for the deposit and dissemination of scientific research documents, whether they are published or not. The documents may come from teaching and research institutions in France or abroad, or from public or private research centers.
L'archive ouverte pluridisciplinaire HAL, est destinée au dépôt et à la diffusion de documents scientifiques de niveau recherche, publiés ou non, émanant des établissements d'enseignement et de recherche français ou étrangers, des laboratoires publics ou privés. 


\title{
What do children understand? Communicating health behavior in a European multicenter study
}

\author{
Antje Hebestreit • Katharina Maria Keimer • Holger Hassel • Annunziata Nappo • \\ Gabriele Eiben • Juan Miguel Fernández • Eva Kovacs • Helen Lasn • \\ Monica Shiakou • Wolfgang Ahrens
}

Received: 1 March 2009/Accepted: 10 December 2009/Published online: 26 February 2010

(C) Springer-Verlag 2010

\begin{abstract}
Background Diet and physical activity are important factors in the prevention of childhood overweight. This article stresses the importance of effective communication for health behavior.

Methods Transcription, description and analysis of standardized focus group discussions (FGD) in seven European countries using standardized questioning routes.
\end{abstract}

On behalf of the IDEFICS Consortium

Annunziata Nappo, Gabriele Eiben, Juan Miguel Fernández, Eva Kovacs, Helen Lasn and Monica Shiakou contributed equally to this work.

A. Hebestreit $(\bowtie) \cdot$ K. M. Keimer $\cdot$ W. Ahrens

Bremen Institute for Prevention Research and Social

Medicine (BIPS), Division of Epidemiological

Methods and Etiologic Research,

University of Bremen,

Linzer St 10,

28359 Bremen, Germany

e-mail: antje.hebestreit@gmx.net

K. M. Keimer

e-mail: keimer@bips.uni-bremen.de

W. Ahrens

e-mail: ahrens@bips.uni-bremen.de

\section{A. Nappo}

Epidemiology \& Population Genetics,

Institute of Food Science \& Technology,

National Research Council,

Via Roma 52, 83100 Avellino, Italy

e-mail: anappo@isa.cnr.it

G. Eiben

Institute of Community Medicine,

Department of Public Health and Community Medicine,

Göteborg University,

Box 454, 40530 Göteborg, Sweden

e-mail: gabriele.eiben@medfak.gu.se
Results Parents are well informed about health-related topics for children, but seem to have difficulties understanding their role in promoting healthy behavior. They mentioned health-related rules, but our results show limited communication between parents and children, and no follow-up of rules. Consequently, children do not understand rules about good health and do not follow them.

\footnotetext{
J. M. Fernández

Universidad de Zaragoza, Edif. Cervantes, $2^{\mathrm{a}}$ planta,

C/ Corona de Aragón, 50.009 Zaragoza, Spain

e-mail: juanfdez@unizar.es

E. Kovacs

National Institute of Health Promotion,

Department of Public Health,

University of Pécs, József A.u.7,

7623 Pécs, Hungary

e-mail: e.k.kovacs@gmail.com

H. Lasn

Chronic Disease Department,

National Institute for Health Development,

Hiiu 42, 11619 Tallinn, Estonia

e-mail: Helen.Lasn@tai.ee

M. Shiakou

Research \& Education Foundation of Child Health, 138, Limassol ave, \#205, 2015 Strovolos, Cyprus

e-mail: mshiakou@hotmail.com

H. Hassel

Hochschule Coburg, University of Applied Sciences,

Friedrich-Streib-Str. 2, 96450 Coburg, Germany

e-mail: hassel@hs-coburg.de
} 
Conclusion Effective and sustainable intervention programs should focus on educational methods and, using parental role modeling, facilitate parents' comprehension of their key role in setting rules and controlling them in order to communicate good health behavior to their children.

Keywords Child obesity . Communication - Focus group . Health behavior IDEFICS

\section{Background}

The increasing prevalence of childhood overweight and obesity enhances the burden for modern health care systems and is a growing public health concern (WHO 2003). Therefore, core aspects of the IDEFICS study intervention program include healthy eating, physical activity (PA) and stress reduction (Bammann et al 2007). The IDEFICS study (Identification and prevention of Dietary- and lifestyleinduced health EFfects In Children and infantS) is an EUfunded project investigating the effect of diet and lifestyle on overweight and obesity in European children aged 2 to 10 years (Ahrens et al. 2006).

Focus group discussions (FGD) were conducted to identify information channels for health behavior, facilitators and barriers in the target groups (children aged 2 to 10 years and parents) to get a deeper understanding of the communication between parents and children. Based on this information, intervention programs can be designed to assist parents to develop clear education and communication strategies. Previous publications have discussed the IDEFICS FGD with a focus on dietary behavior and physical activity, especially the barriers, facilitators and attitudes of parents and children (Haerens et al. 2009). The focus of our article is on the communication of health behavior between parents and children and what children need to understand health messages.

\section{Methods}

FGDs were used for the development of the IDEFICS intervention and were carried out from February to April 2007 in eight IDEFICS intervention centers. FGDs were carried out only in the intervention regions of the IDEFICS study in order to involve the target groups (families, children, teachers and educators) in the development of the intervention program. FGDs were identified as especially useful for the development of the intervention since they assess the need of the target group and assist in the development of effective health promotion programs. This method allows the researcher to gain a broad perspective on a group of individuals that will be affected by the intervention (Petersen-Sweeney 2005).

A focus group describes a group of individuals with a similar background or experience assembled to discuss a topic of relevance (Freeman 2006; Powell and Single 1996); in the IDEFICS study, motivating factors for children to eat healthily and to be physically active were discussed. Focus groups were homogenous with respect to their socioeconomic level and for children with respect to gender (boys and girls in different groups). However, focus groups were heterogeneous with respect to gender in the adult groups (mixed groups of women and men). Due to the age-related problems with filling out questionnaires, demographic variables [e.g., socioeconomic status (SES)] were not assessed in children. The socioeconomic status of parents, educators and teachers was determined through the recruitment channels described below.

The present publication focuses on the results of FGDs held in Cyprus (Strovolos), Estonia (Tallinn), Germany (Bremen), Hungary (Pécs), Italy (Avellino), Spain (Zaragoza) and Sweden (Gothenburg), since these showed a variety of perspectives on the research question "what do children understand" and were hence of particular interest. Main results from all partners' FGDs have been published elsewhere (Haerens et al. 2009).

Recruitment of participants followed similar patterns in all countries: In Cyprus, Estonia, Germany and Spain, participants were recruited through various schools or preschools in deprived/non-deprived areas, involving the nurses/teachers and headmasters. In Sweden participants were recruited by telephone contact through the research institute directly. In Hungary, the children were recruited through existing contacts in a different study. Parents were recruited through the schools and kindergartens in areas with a low/medium SES population. In Italy parents and children were invited to participate in the focus groups (unpublished reports). The research focus of this qualitative method is to highlight the communication between parents and children concerning nutrition and physical activity. Hence, not only obese children and their parents were included.

For the exact numbers of participants in each country's FGD, see Table 1.

The FGDs were timed to last around $2 \mathrm{~h}$; sessions with children were timed to be shorter (approximately $30 \mathrm{~min}$ ). The shorter time span is recommended for FGDs with children. All FGDs were undertaken in an environment familiar to the participants and were offered at different times of the day to increase participation (University of Ghent 2006; Morgan 1998; Krueger 1998).

All FGDs were "led" by a trained moderator, whose role was to guide the discussion and listen to what was said but not to participate, share views, engage in discussions or 


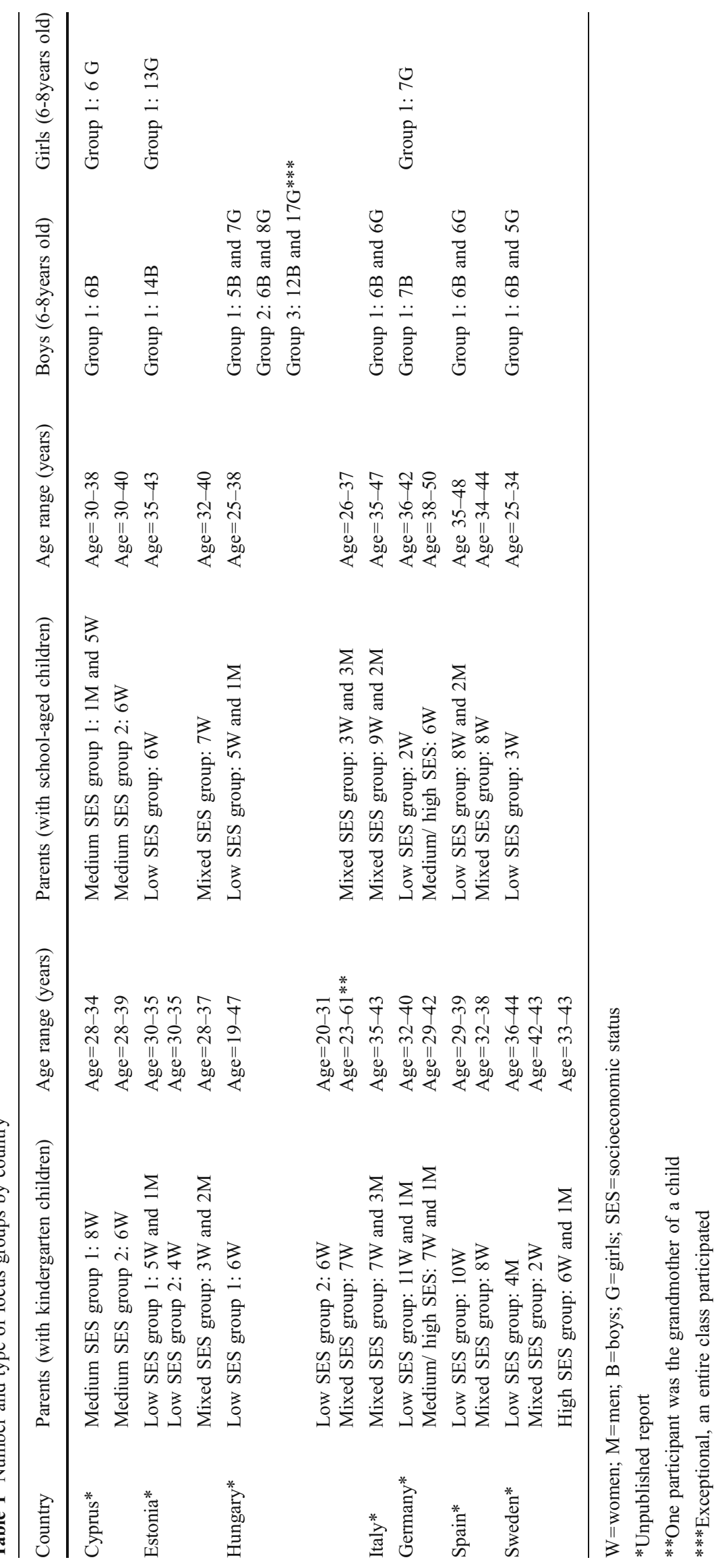


shape the view of the outcome (Morrison-Beedy et al. 2001). The moderator was familiar with the questioning route, which covered key questions on healthy eating and PA (Beyea and Nicoll 2000). A co-moderator assisted the moderator during all FGDs (Pelz et al. 2004). After each session, the moderator and co-moderator summarized the main points to compare this summary with the transcription later on (University of Ghent 2006; Krueger 1998).

All FGDs were audio-taped. Each tape was transcribed, described and analyzed in the local language of the participating country. The transcripts were analyzed by grouping the comments into categories (e.g., diet, PA, barriers, facilitators, family, parents, children). In this way, specific themes could be easily identified and summarized. The standardized questioning route served as the basic outline for selecting the most important quotes, those that delivered valuable information for the development of the IDEFICS intervention (Haerens et al. 2009). Focus group summary reports were written using a standardized template that was developed for each of the moderators and comoderators to complete in English based on the audio tapes of the sessions in the original language. The extensive summary reports for each center detailed all tape recorded results around the key questions using the standardized templates.

\section{Results}

A total of 186 parents participated in the FGDs (164 women; 22 men). Sixty-eight boys between 6 and 8 years of age and 75 girls in the same age group participated (see Table 1).

All results are based on the analysis of the FGDs of the participating IDEFICS centers and have been generalized to fit the purpose of shaping an IDEFICS intervention program.

This publication focuses on communication channels between children and parents in the IDEFICS centers. First, the parents' attitudes regarding a healthy diet and PA were worked out as well as how they understoond their own role, e.g., setting and controlling rules or role modeling. The second and third steps summarize how parents effectively implement a healthy diet and PA in the children's lifestyles as well as barriers to and facilitators of the implementation. Finally, the children's own understanding of rules, controlling them and role modeling are examined. Following this line of argument, we will determine to what extent the participating families were able to communicate health rules successfully (see Table 2).

Findings about healthy diet: parent's attitude and self-concept

In all countries, interviewed parents asserted the presence of rules regarding healthy eating habits and saw their main responsibility as "strengthening the child's individual responsibility for healthy eating," in setting a good example, in enhancing the availability of healthy foods and in limiting unhealthy foods and soft drinks at home. During weekends and on special occasions, parents allow their children to eat what they like and allow some junk food (Sweden, Spain, Cyprus, Hungary). German and Hungarian parents set rules for family meals with table rules, and a few parents do not allow eating in front of the TV (Germany, Italy). Also, Spanish and Hungarian parents report the use of sweets as rewards.

Findings about healthy diet: implementation and barriers/facilitators

Generally parents decide what kind of food the children eat at home (Sweden) and offer a wide variety of foods (Italy). Estonian parents often warm up leftovers for dinner, and soft drinks are available. In general, they "do not force children into healthy eating."

Parents reported more on barriers than on facilitators, like the lack of time because of a busy work schedule and lack of money to buy high quality food: convenience food is perceived to require less preparation time and to be cheaper. Parents consider the different food preferences of children and adults as a main problem and therefore feel pressure from children, who prefer fast food; this latter influence is reinforced by TV advertisements. Another main barrier to the parents' opinion is the lack of communication between children and parents; also, other family members (e.g., grandparents) break existing rules.

The few facilitators mentioned were: "healthy food availability at home" (e.g., fruit and vegetables cut in handy pieces, drinking water) as well as parental consumption of healthy foods.

Findings about healthy diet: understanding and behavior of the child

When asked, children were unaware of existing rules or limitations (Germany, Estonia, Hungary, Spain), or mentioned various rules about the availability of sweets (Sweden). Only Italian children mentioned one clear rule: "no watching TV while eating," and Hungarian children clearly understood the family eating traditions and table culture. Cypriot children followed the parent's eating habits and listed the consumption of fruits and vegetables or the restriction of sweets at home.

Findings about PA: parent's attitude and self-concept

In all countries, parents believe that PA and outdoor activities are good for the child. Italian and German parents 


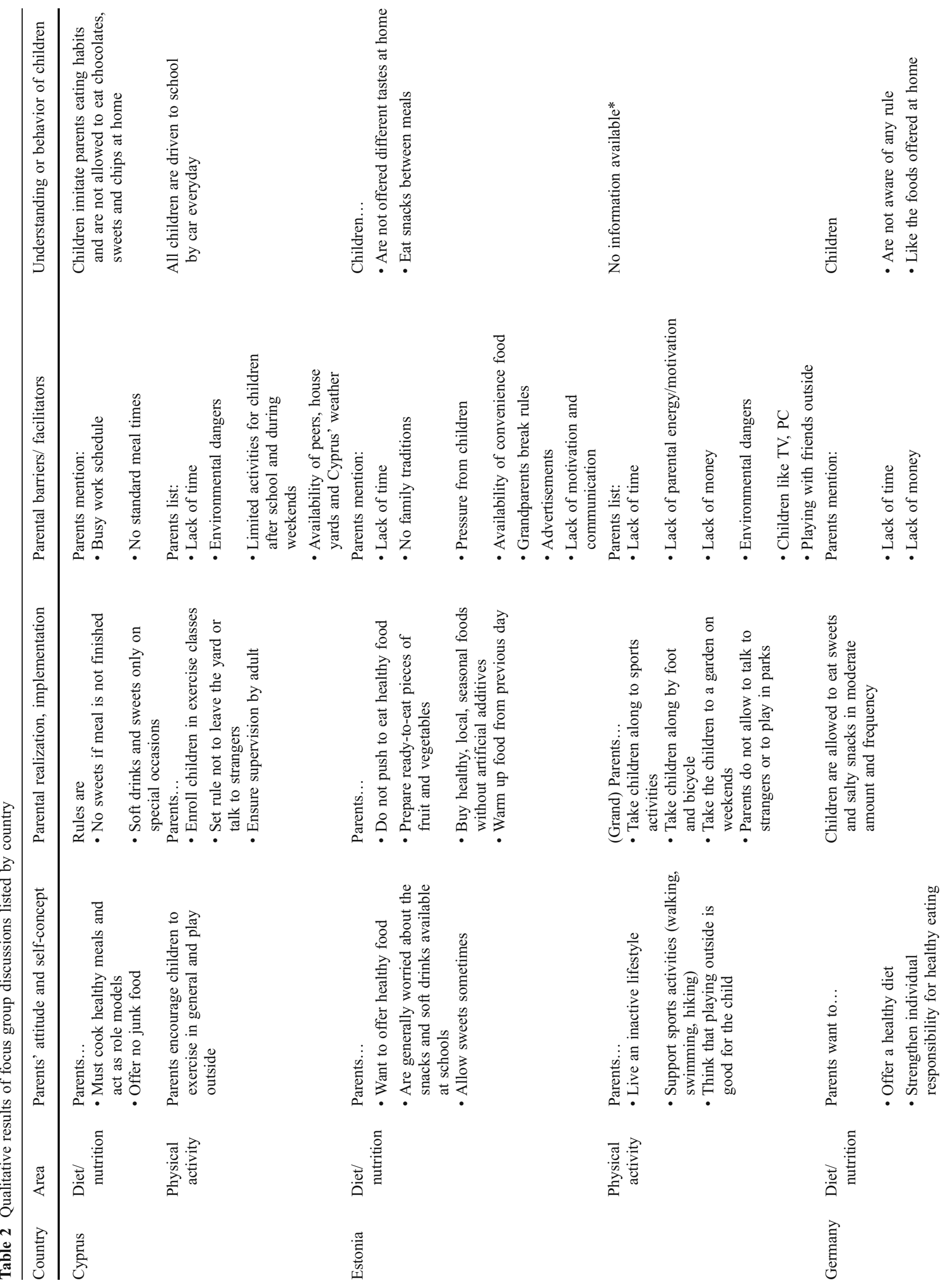




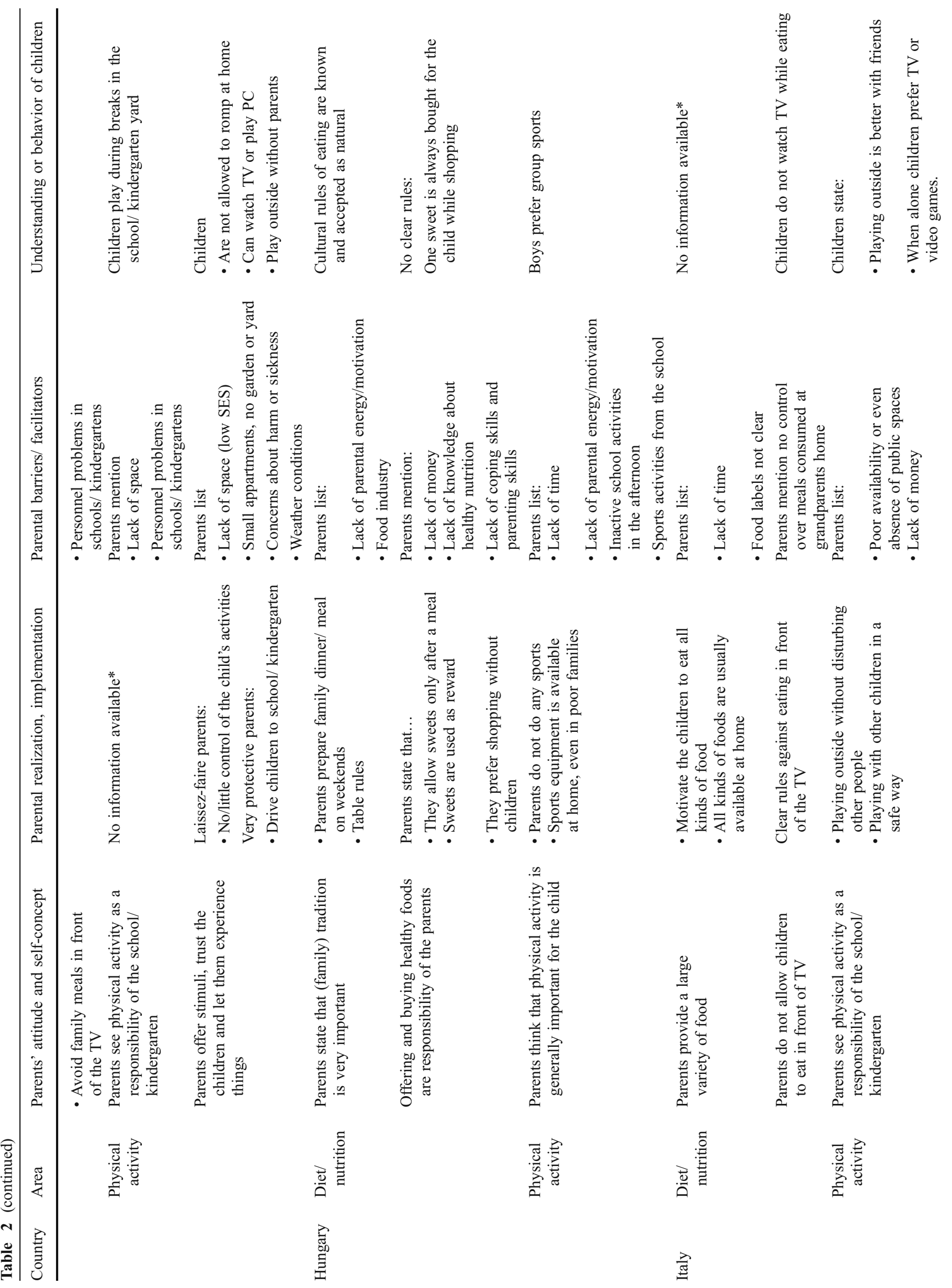




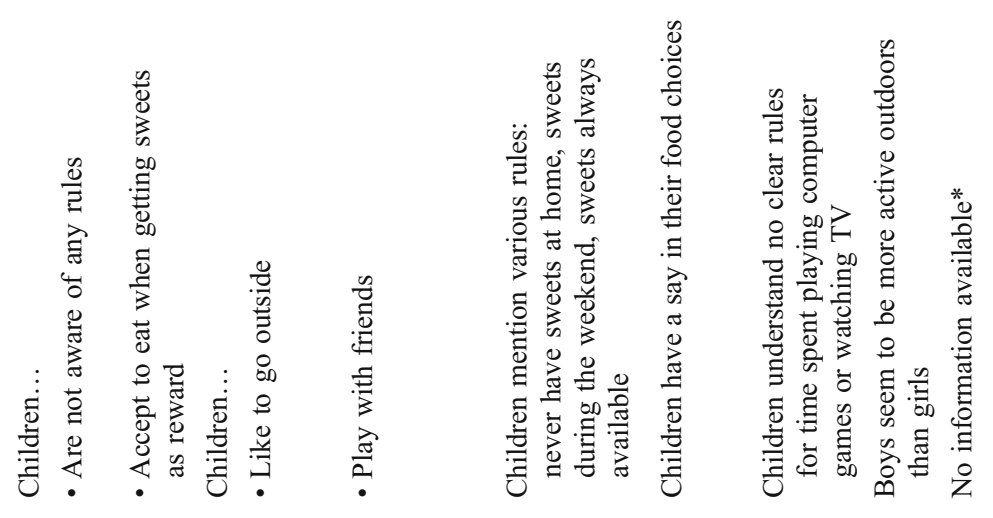
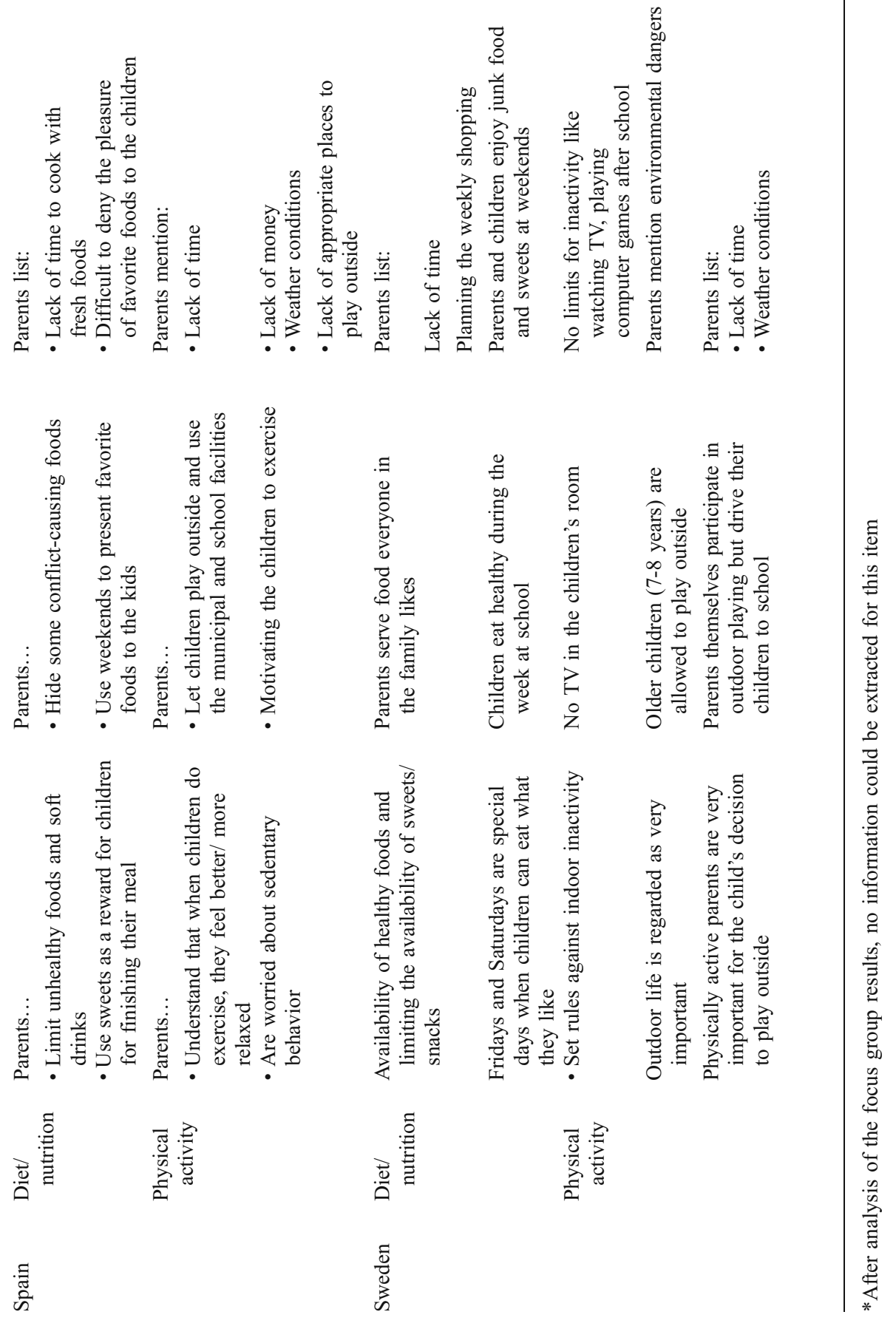
see PA as the responsibility of the school/kindergarten. However, they stated that they offer stimuli and motivate children to play outside. Cypriot parents also indicated the school's responsibility for PA, but in a different context: due to a busy school schedule and a lot of homework, children do not find the time for playing outdoors or sports. Parents set rules against indoor inactivity (Germany, Sweden) and see their responsibility in setting a good example (Estonia, Sweden).

Findings about PA: implementation and barriers/ facilitators

In all countries, parents set clear rules regarding outdoor safety ("do not talk to strangers," it is allowed to talk and play with other kids, and "avoid parks and strange groups of teenagers"), but offer support in different ways and to different degrees. Swedish and German parents drive their children to school, but confirmed their own participation in playing outdoors, where Spanish parents motivate children to make more use of activities offered by the school or municipal facilities. Hungarian parents describe an inactive lifestyle and do not act as role models.

The most mentioned barriers in all countries were the lack of space, the lack of time, lack of parental motivation, and concerns about harm or sickness because of bad weather and environmental dangers. Also high costs for equipment and sports club fees and the attractiveness of TV and PC games were mentioned as barriers. Facilitators were: playing with friends and siblings, and if children were allowed to get dirty (proof of fun play).

Findings about PA: understanding and behavior of the child

IDEFICS children mention that they are not allowed to romp at home, so they watch TV or play with the PC when the weather is bad or when they are alone at home (Germany, Italy, Sweden). When the weather allows for it, they play outside with friends or siblings after finishing homework (Sweden, Cyprus, Italy, Spain).

\section{Discussion}

A positive energy balance (increase of body fat) results from long-term low energy expenditure while the energy intake is high. Behavior patterns that lead to the development of a positive energy balance are: frequent access to a comprehensive food supply together with a reduced PA rate (Maffeis 2000). Here, behavior is mainly influenced by the modern environment, including food availability, portion sizes, media consumption and the degree of automation (Davison and Lawson 2006; Nielsen and Popkin 2003). However, parents also influence the child's eating habits and PA levels, mainly through three different channels: setting a good example (role modeling), conveying rules and controlling the rules (rigid or flexible). The quality of control seems to be important since it determines the success of an intervention: foods as a reward or punishment and rigid portion sizes may enhance eating disorders (Birch and Fisher 1995).

Role modeling

Research shows that parents mainly influence the child's eating behavior through their own behavior (Birch and Fisher 1995). This was associated with a higher fruit juice and vegetable intake among pre-school children and with a higher calcium intake from cow's milk among adolescent girls (Cullen et al. 2001; Lee and Reicks 2003). Our FGD results show that Cypriot parents seem to be good role models: their children confirmed identical eating habits and preferences, and identical foods available at home. This evidence of conformity indicates that the consistent behavior of the parents is understandable for the children, and as a result they imitate the parent's healthy eating habits.

Regarding PA, children with active parents show a significantly higher activity level than children with inactive parents. Here, mothers tend to support PA through logistic support (e.g., transport), whereas fathers preferably join the activities (Davison et al. 2003; Nelson et al. 2006).

The Swedish FGD revealed that parents give the impression of leading active lifestyles, but drive the children to school. When playing outside, Swedish children play with siblings or friends, but parents do not join them. Here parents do not act as role models, even if they consider parental role modeling as an important motivator.

Consistent role modeling may enhance children's understanding and acceptance of a healthy diet and regular (outdoor) PA in order to prevent overweight (Ritchie et al. 2005). Our results suggest that healthy eating may be easier to realize on a daily basis than living an active lifestyle. Hence, an effective intervention program should support parents with ideas and activities that are easy to implement, even on busy days and in all kinds of weather.

Rules

Birch (1999) found that strict control of eating by the parents is associated with obesity among girls. Parents should aim to develop their children's capacity to selfcontrol meal timing, meal size and food selection, because children exhibit an innate ability to regulate their energy intake (Birch and Fisher 1998; Fox et al. 2006).

Spanish and Cypriot parents restrict unhealthy foods such as sweets or salty snacks. The restriction of unhealthy 
foods is one (parental) tool to increase the consumption of healthy foods. However, research shows that restricting certain foods enhances their desirability for children. Thus, intake increases when the food is available (Birch and Fisher 1995; Birch 1999; Fisher and Birch 1999).

Parents often have clear attitudes about healthy eating. In reality behavior is contradictory to attitude. As was seen in Hungary and Spain, parents use sweets as a reward. Also Estonian children eat unhealthy snacks between meals, and Swedish children mention different rules for the availability of sweets and junk food. In all four countries, the communication of rules between children and parents may be lacking or ambiguous. As a result, children are confused or unaware of rules and therefore react in contradictory ways.

By contrast, Cypriot children understand the rules and follow them-even if they preferred junk food. Here the consistent compliance with the rules by the parents leads to healthier eating behavior of the children. In terms of cultural rules, Estonian and Cypriot parents fail to establish eating traditions and family meal times, even though they highlight their importance. Unlike Hungarian parents, they clearly state cultural rules, and the children understand and accept them. Italian and German parents require the family to eat together and not in front of the TV. When asked, German children are unaware of this rule and eat in front of the TV. In contrast, Italian children are aware of this rule. This example demonstrates that German parents do not ensure adherence to the rule, whereas Italian parents obviously communicate the consequences for a breach with their children.

Fewer children walk or bike to school, but rather use automated transport (bus, parental transport) (Carver et al. 2008; Goran and Treuth 2001). Carver mentions that 'stranger danger' and road safety are stronger arguments than health aspects for parents, who feel themselves under social pressure to chauffeur their children, since letting the children walk to school could be seen as being less caring (Carver et al. 2008). Also Swedish, German, Hungarian and Cypriot parents do not allow their children to walk or cycle to school and consequently increase their moderate activity before and after school.

Especially moderate activity seems to counteract obesity most efficiently, particularly when individuals change from sedentary behavior (Davison and Lawson 2006; Carrel et al. 2005; Strauss et al. 2001; Robinson 1999). One successful approach to prevent obesity among 3- to 7-year-old children is increasing the time spent physically active instead of watching television (Jago et al. 2005). The FGD results show that parents (Estonia, Germany, Italy, Sweden) set rules against watching $\mathrm{TV}$ and playing with the $\mathrm{PC}$, so that the children are more physically active. But they also mention barriers: lack of time, their own laziness, lack of space and environmental dangers (for outdoor activities). As a result, children (in Estonia, Germany, Italy) watch TV and play with PCs, and are not aware of the screen time restriction.

The findings may encourage parents to communicate clear regulations and to adhere to the rules consistently; in doing so, they can help children understand and accept rules.

\section{Control}

Availability and accessibility are important predictors of children's food choices and food intake (Cullen et al. 2001). This type of control, emphasizing the availability of healthy foods and enhancing healthy food choices, is stated by all parents and supported by the literature (Birch and Fisher 1995; Birch 1999; Orrell-Valente et al. 2007). In most countries, however, parents accept junk food and sweets once in a while and state that children should have access in order to develop individual responsibility and self-control. These contradictory findings show that parents do not understand their role: offering a variety of healthy foods plus controlling the child's healthy food choices. In most countries, strengthening the child's individual responsibility was impeded by a lack of money for fresh foods, seasonal changes and the child's food preferences, and the lack of time on work/school days is the most important barrier. This can be seen in Estonia: after school, children eat anything they find at home and later parents tend to offer snacks or re-warm meals for dinner. There is no family eating routine, which has been described to be important (Gillman et al. 2006).

In general, a lack of communication and motivation between parents and children seems to be a problem: parents set rules but they do not control the children's food choices or make healthy foods available at home.

Our results illustrate notably that parent-child communication is one key element of health education. We also found that parents were well informed about the benefits of a healthy diet and PA for their children. Even though parents have a clear attitude about a healthy family lifestyle, we found that implementing rules for good health and a healthy lifestyle seemed to be difficult in the daily routine. How can the gap between a healthy parental attitude and the children's understanding be bridged? Our findings reveal that the development of effective and sustainable intervention programs requires educational methods and communication channels for parents. They can help parents to understand their key role, using parental role modeling, rules and control mechanisms to communicate health behavior to their children, as also stated by Golan and Crow (Golan and Crow 2004). According to our findings, an effective intervention program should consider that role modeling (healthy parental lifestyle) and responsive control 
(supporting PA and availability of healthy foods) result in a healthier diet (smaller portions, large variety, less sugar and less fat intake) and higher PA levels.

Thanks to the design of the IDEFICS FGD, parents trying to make socially desirable statements was a minor problem: after comparing parental answers with the children's statements, the deficiencies in health communication were obvious. Statements that illustrate the parental attitude to a healthy lifestyle may be colored by social desirability, but also show the high level of information due to media campaigns, intervention programs and easy media access. So, those communication channels and instruments work well for the dissemination of health messages in adults. However, the fact that the children were not aware of restrictions supports the importance of intervention activities and communication strategies suitable for children.

One limitation of this study is the questioning route of the FGD; it did not query the quality of communication (rigid or flexible), and our results do not provide very detailed information on how exactly rules are communicated and if consequences follow. Hence, we recommend including questions about communication channels that aim to identify the most effective intervention strategies when developing FGD questioning routes.

Inexplicably children and parents in all countries associate the "healthy eating" concept with the quality of foods, but not with quantity, even though portion sizes and meal frequencies are part of the overeating problem. Parents with a weak or no control over their own eating behavior (portion size, meal frequency) may promote the development of eating disorders and in consequence overweight in their children (Birch and Davison 2001; Contento et al. 1993). Children, like adults, eat more when large potions are available and energy intake is high due to overeating (Nicklas et al. 2001), whereas eating frequency is inversely associated with a lower degree of adiposity (Barba et al. 2006; Toschke et al. 2005). Regarding the development of effective intervention programs, education mechanisms concerning healthy quantities of food and frequencies of eating should be considered.

Mechanisms leading to a healthier lifestyle through PA and nutrition are definitely very complex. In addition to other factors, communication channels obviously seem to play an important role in the multifactorial problem of "childhood obesity."

Acknowledgements This work was done as part of the IDEFICS Study (www.idefics.eu). We gratefully thank all partners of the IDEFICS consortium.

The information in this document reflects the author's view and is provided as is. No guarantee or warranty is given that the information is fit for any particular purpose. The user thereof uses the information at their sole risk and liability.
Source of Support: European Community within the Sixth RTD Framework Programme [contract no. 016181 (FOOD)].

Competing interests No conflict of interest declared.

\section{References}

Ahrens W, Bammann K, De Henauw S et al (2006) Understanding and preventing childhood obesity and related disordersIDEFICS: a European multilevel epidemiological approach. Nutr Metabol Cardiovasc Dis 16(4):302-308

Bammann K, Peplies J, Sjöström M et al (2007) Assessment of diet, physical activity and biological, social and environmental factors in a multi-centre European project on diet- and lifestyle-related disorders in children (IDEFICS). J Public Health 14(5):279-289

Barba G, Troiano E, Russo P, Siani A (2006) Total fat, fat distribution and blood pressure according to eating frequency in children living in southern Italy: the ARCA project. Int J Obes (Lond) 30(7):1166-1169

Beyea SC, Nicoll LH (2000) Learn more using focus groups. AORN J 71(4):897-900

Birch LL (1999) Development of food preferences. Annu Rev Nutr 19:41-62

Birch LL, Davison KK (2001) Family environmental factors influencing the developing behavioral controls of food intake and childhood overweight. Pediatr Clin North Am 48(4):893-907

Birch LL, Fisher JA (1995) Appetite and eating behavior in children. Pediatr Clin North Am 42(4):931-953

Birch LL, Fisher JO (1998) Development of eating behaviors among children and adolescents. Pediatrics 101:539-549

Carrel AL, Clark RR, Peterson SE, Nemeth BA, Sullivan J, Allen DB (2005) Improvement of fitness, body composition, and insulin sensitivity in overweight children in a school-based exercise program: a randomized, controlled study. Arch Pediatr Adolesc Med 159(10):963-968

Carver A, Timperio A, Crawford D (2008) Playing it safe: the influence of neighbourhood safety on children's physical activityA review. Health Place 14(2):217-227

Contento IR, Basch C, Shea S et al (1993) Relationship of mothers' food choice criteria to food intake of preschool children: identification of family subgroups. Health Educ Q 20(2):243-259

Cullen KW, Baranowski T, Rittenberry L, Cosart C, Hebert D, de Moor C (2001) Child-reported family and peer influences on fruit, juice and vegetable consumption: reliability and validity of measures. Health Educ Res 16(2):187-200

Davison KK, Lawson CT (2006) Do attributes in the physical environment influence children's physical activity? A review of the literature. Int J Behav Nutr Phys Act 3:19

Davison KK, Cutting TM, Birch LL (2003) Parents' activity-related parenting practices predict girls' physical activity. Med Sci Sports Exerc 35(9):1589-1595

Fisher JO, Birch LL (1999) Restricting access to foods and children's eating. Appetite 32(3):405-419

Fox MK, Devaney B, Reidy K, Razafindrakoto C, Ziegler P (2006) Relationship between portion size and energy intake among infants and toddlers: evidence of self-regulation. J Am Diet Assoc 106:77-83

Freeman T (2006) 'Best practice' in focus group research: making sense of different views. J Adv Nurs 56(5):491-497

Gillman MW, Rich-Edwards JW, Huh S et al (2006) Maternal corticotropin-releasing hormone levels during pregnancy and offspring adiposity. Obes Res 14(9):1647-1653 
Golan M, Crow S (2004) Parents are key players in the prevention and treatment of weight-related problems. Nutr Rev 62(1):39-50

Goran MI, Treuth MS (2001) Energy expenditure, physical activity, and obesity in children. Pediatr Clin North Am 48(4):931-953

Haerens L, Bourdeaudhuij I, Barba G et al (2009) Developing the IDEFICS community based intervention program to enhance eating behaviors in 2-8 year old children: findings from focus groups with children and parents. Health Educ Res 24(3):381-393

Jago R, Baranowski T, Baranowski JC, Thompson D, Greaves KA (2005) BMI from 3-6 y of age is predicted by TV viewing and physical activity, not diet. Int J Obes (Lond) 29(6):557-564

Krueger RA (1998) Moderating focus groups (Focus Group Kit 4). Sage Publishing, Thousand Oaks

Lee S, Reicks M (2003) Environmental and behavioral factors are associated with the calcium intake of low-income adolescent girls. J Am Diet Assoc 103(11):1526-1529

Maffeis C (2000) Aetiology of overweight and obesity in children and adolescents. Eur J Pediatr 159:35-44

Morgan DL (1998) Planning focus groups (Focus Group Kit 2). Sage Publishing, Thousand Oaks

Morrison-Beedy D, Cote-Arsenault D, Fischbeck Feinstein N (2001) Maximizing results with focus groups: moderator and analysis issues. Appl Nurs Res 14:48-53

Nelson JA, Carpenter K, Chiasson MA (2006) Diet, activity, and overweight among preschool-age children enrolled in the special supplemental nutrition program for women, infants, and children (WIC). Prev Chronic Dis 3(2):A49

Nicklas TA, Baranowski T, Cullen KW, Berenson G (2001) Eating patterns, dietary quality and obesity. J Am Coll Nutr 20(6):599-608
Nielsen SJ, Popkin BM (2003) Patterns and trends in food portion sizes, 1977-1998. JAMA 289(4):450-453

Orrell-Valente JK, Hill LG, Brechwald WA, Dodge KA, Pettit GS, Bates JE (2007) "Just three more bites": an observational analysis of parents' socialization of children's eating at mealtime. Appetite 48(1):37-45

Pelz C, Schmitt A, Meis M (2004) Knowledge Mapping als Methode zur Auswertung und Ergebnispräsentation von Fokusgruppen in der Markt- und Evaluationsforschung. FQS: Forum Qual Soz forsch 5(2):35

Petersen-Sweeney K (2005) The use of focus groups in pediatric and adolescent research. J Pediatr Health Care 19:104-110

Powell RA, Single HM (1996) Focus groups. Int J Qual Health Care 8 (5):499-504

Ritchie LD, Welk G, Styne D, Gerstein DE, Crawford PB (2005) Family environment and pediatric overweight: what is a parent to do? J Am Diet Assoc 105:70-79

Robinson TN (1999) Reducing children's television viewing to prevent obesity: a randomized controlled trial. JAMA 282 (16):1561-1567

Strauss RS, Rodzilsky D, Burack G, Colin M (2001) Psychosocial correlates of physical activity in healthy children. Arch Pediatr Adolesc Med 155(8):897-902

Toschke AM, Küchenhoff H, Koletzko B, von Kries R (2005) Meal frequency and childhood obesity. Obes Res 13:1932-1938

University of Ghent (2006) Study manual for qualitative research and documentation sheets for qualitative research. Internal Document

WHO Geneva (2003) Diet, Nutrition and the Prevention of Chronic Diseases. WHO Technical Report Series 1-160 